\title{
Hsa-let-7g miRNA regulates the anti-tumor effects of gastric cancer cells under oxidative stress through the expression of DDR genes
}

\author{
Haiqing Hu${ }^{1}$, Xuanzhong Zhao ${ }^{2}$, Zhao Jin² and Mingxing Hou ${ }^{2}$ \\ ${ }^{1}$ Department of Gastroenterology and Hepatology, the Affiliated Hospital of Inner Mongolia Medical University, \\ 1 Tongdao North Road, Hohhot, Inner Mongolia, 010050, China \\ ${ }^{2}$ Gastrointestinal surgery, the Affiliated Hospital of Inner Mongolia Medical University, \\ 1 Tongdao North Road, Hohhot, Inner Mongolia, 010050, China
}

(Received October 30, 2014; Accepted February 14, 2015)

\begin{abstract}
Oxidative stress is linked to increased risk of gastric cancer (GC). Recent reports have found that hsa-let-7g microRNA (miRNA) has properties of anti-tumor and resistance to damages induced by oxidized low-density lipoprotein (ox-LDL). Dysregulation of hsa-let-7g was present in GC in vivo and in vitro under exogenous stress. However, we didn't know whether there are regulatory mechanisms of hsa-let-7g in GC under oxidative stress. This study was aimed at investigating the effects of hsa-let-7g microRNA (miRNA) on GC under oxidative stress. The results showed that $\mathrm{H}_{2} \mathrm{O}_{2}$ induced the increase of DNA damage response (DDR) genes (ATM, H2AX and Chk1) and downregulation of hsa-let-7g in GC cells. Further study confirmed Hsa-let-7g caused the apoptosis and loss of proliferation in GC cells exposed to $\mathrm{H}_{2} \mathrm{O}_{2}$ associated with repression of DDR system. Yet, we found let-7g didn't target DDR genes (ATM, H2AX and Chk1) directly. In addition, data revealed hsa-let-7g miRNA increased the sensitivity of GC to X-rays involving in ATM regulation as well according to application of X-rays (another DDR inducer). In conclusion, Hsa-let-7g miRNA increased the sensitivity of GC to oxidative stress by repression activation of DDR indirectly. Let-7g improved the effects of X-rays on GC cells involving in DDR regulation as well.
\end{abstract}

Key words: Gastric cancer, MicroRNA, Hsa-let-7g, Oxidative stress, DNA damage response

\section{INTRODUCTION}

The prevalence of gastric cancer (GC) is particularly serious in Asian countries (Leung et al., 2008). Newly diagnosed GC cases in Asian countries accounted for about three-quarters of the world total in 2008 (Shen et al., 2013). To date, the 5-year survival rate of GC patients is less than 15\% (Correa, 2004). However, the pathogenesis of GC is largely unknown.

Nutritional, microbial, and genetic factors have been proposed to exert effects on the multistep and multifactorial process, where oxidative stress is involved (Nair et al., 2000). The normal level of reactive oxygen species (ROS) is favorable to exhibit physiological functions (Valko et al., 2006; D'Autreaux and Toledano, 2007). But, luxuriant ROS, which is denoted as oxidative stress, is harmful to the body (D'Autreaux and Toledano, 2007). It has been confirmed that oxidative stress induced by free radicals is highly related to the development of several diseases, including cardiovascular, cancer, and chronic inflammation as causing DNA and protein modification and lipid peroxidation (Oberley, 2002; Hussain et al., 2003; Sanders et al., 2004). It is known that the gastric epithelium continuously undergoes oxidative stress owing to ingested food and cigarette smoke and inflammation induced by Helicobacter pylori infection, which could increase the risk of mucosal homeostasis collapsing (Gencer et al., 2013; Farinati et al., 2008). It happens that gene expression profiles and protein structure and function have been changed to result in tumor promotion once mucosaa homeostasis collapses (Tang et al., 2010; Lowy et al., 2006). So, it is inadvisable to ignore the relationships between oxidative stress and GC. Yet, the precise molecular mechanisms about the relationships remain

Correspondence: Mingxing Hou (E-mail: houmx1964@sohu.com) 
unclear.

MicroRNAs (miRNAs), small single-stranded RNA molecules containing about 22 nucleotides, are noncoding RNAs molecules which can bind the 3'-untranslated region of target messenger RNA (mRNA) to regulate diverse gene expression. At present, the role of some miRNAs has been revealed to associate with oxidative stress in GC. Aberrant miRNA-21 was found under oxidative stress in GC tissues and GC cells. Further study revealed oxidative stress promoted gastric carcinogenesis according to upregulating miR-21 expression (Tu et al., 2014). Excessive ROS induced by macrophages stimulated the promotion of GC growth according to suppression of miR-328 (Ishimoto et al., 2014). Several recent studies have indicated that the dysregulation of hsa-let-7g was present in GC in vivo and in vitro under exogenous stress (Wu et al., 2011; Hummel et al., 2010). Moreover, a negative feedback modulation has been reported between Hsa-let-7g miRNA with oxidative stress in some diseases (Chen et al., 2011). Thus, we are interested in whether there are regulatory mechanisms of hsa-let-7g in GC under oxidative stress.

ROS induced by oxidative stress stimulates DNA damage response (DDR), which is activated upon DNA damage (Chen et al., 2012). Cancer cells often display significant modification at the DDR-associated factors and develop inhibition to DNA damage-inducing agents (Tessitore et al., 2014). In the last decade, it has been documented that miRNAs were involved in the regulation of DNA damage/repair process in some cancers $(\mathrm{Hu}$ et al., 2010; Wang et al., 2011; Crosby et al., 2009). We have found some miRNAs possess the regulatory effects on radiosensitivity of cancer (Zhao et al., 2012). Reviews have concluded MiRNAs involved in the regulation of DNA damage/repair mechanisms can be considered markers to predict the response to radiotherapy (Zhao et al., 2012; Tessitore et al., 2014). In terms of GC, both miR-300 and miR-642 potentially regulated DNA damage and repair pathway-related genes by using miRNA microarray after two clinical GC samples exposed to $\mathrm{X}$-rays (He et al., 2014). Another report found that miR375 targets p53 to regulate the response to ionizing radiation and etoposide treatment in several gastric cancer cell lines (Liu et al., 2013). miR-221 and miR-222 regulate radiosensitivity of gastric carcinoma cells (SGC7901 cells) as well (Chun-Zhi et al., 2010). It's interesting to explore whether there are other microRNAs involved in the regulation of DDR in GC.

In this study, we focused on the expression of DDR genes and miRNA hsa-let-7g in GC cells exposed to $\mathrm{H}_{2} \mathrm{O}_{2}$. Further study was to investigate the effect of hsa- let- $7 \mathrm{~g}$ on $\mathrm{GC}$ and the crosstalk between hsa-let- $7 \mathrm{~g}$ with DDR genes under oxidative stress. Moreover, experiments were performed to assess potential application value of hsa-let-7g in anticancer therapeutics of GC.

\section{MATERIALS AND METHODS}

\section{Cell lines, cell culture and treatments}

Human GC cell line (AGS) was acquired from American Type Culture Collection (ATCC, Rockville, MD, USA). AGS cells were grown in DMEM (Gibco, Invitrogen, Carlsbad, CA, USA) with $10 \%$ FBS in a humidified incubator containing $5 \% \mathrm{CO}_{2}$ at $37^{\circ} \mathrm{C}$. Cells were subcultured after reaching $80 \%$ confluence. $\mathrm{H}_{2} \mathrm{O}_{2}$ (SigmaAldrich, St. Louis, MO, USA) was diluted in serumfree DMEM. Cells were treated with $\mathrm{H}_{2} \mathrm{O}_{2}(100 \mu \mathrm{M}$ or $200 \mu \mathrm{M}$ ) for 6,12 or $24 \mathrm{hr}$ when cells were confluent at $90 \%$. Total RNA or proteins were extracted at indicated time points. Human embryonic kidney epithelial cells (293 T cells) were grown in DMEM with $10 \% \mathrm{FBS}$ in a humidified incubator containing $5 \% \mathrm{CO}_{2}$ at $37^{\circ} \mathrm{C}$. Hsa-let- $7 \mathrm{~g}$ mimics (miR mimics) and miRcontrol, purchased from GenePharma (GenePharma, Shanghai, China), were transfected into AGS cells at $50 \mathrm{nM}$ concentration respectively. All cellular transfections were conducted using Lipofectamine 2000 (Invitrogen).

\section{RNA extraction and quantitative real-time polymerase chain reaction (qRT-PCR)}

Total RNA was extracted from cells with RNeasy kit (Qiagen, Valencia, CA, USA). qRT-PCR was conducted on ABI 7500 with SYBR green PCR kits (Applied Biosystems). GAPDH gene was named as endogenous control. Cellular miRNA was isolated using the mirVana miRNA Isolation Kit (Ambion, Austin, TX, USA). MirVana qRT-PCR miRNA Detection Kit (Ambion) and qRT-PCR Primer Sets (Ambion) was used. The U6 small nuclear RNA was internal control of miRNAs. The data were normalized by $2^{-\Delta \Delta \mathrm{Ct}}$ method as relative quantification. The primers used were as follows. ATM (GenBank accession number NM_000051.3): F:5' -TGG GCT CTG GAA TCA TAC GGC-3', R: 5'-TAA CGC TCA CGA GTG CTC ACC AC-3'. Chk1 (GenBank accession number AF016582.1):F: 5'- AAC GCC TTC CTT GAT GGA AT -3' and R:5'-GCGACTTGAACGGAATATCTGT -3'. H2AX (GenBank accession number NM_002105.2):F: 5'- CCC TCG GGC GGC AAG AA -3' and R: 5'- GGA GGG CGG ACG GCG GAC AGG -3'. GAPDH: F:5'-TTT TCC CTC TTC TTG ACT CAC CC-3' and R: 5'- GTG CCT TTC ATT CCA TCC AGC-3'. 
Let-7g regulates DDR to repress GC under stress

\section{Apoptosis and viability assay}

Cellular apoptosis was assessed using Annexin-V-fluorescein isothiocyanate (Annexin V-FITC) apoptosis detection kit (Sigma-Aldrich) according to the manufacturer's instructions (KeyGen Biotech., Nanjing, China). Briefly, cells were harvested after indicated treatments. Then cell suspensions were fixed overnight with ice-cold 70\% ethanol. Next, the fixed cells were stained with propidium iodide or annexin V-FITC after centrifugation and resuspensions. Analyses were performed with flow cytometer (BD FACScan). Data were expressed as the percentage of apoptotic cells from the total cells. For viability assay, cells with indicated treatments were incubated in CCK-8 (Dojindo, Kumamoto, Japan). The $450 \mathrm{~nm}$ absorbance of each well was assayed after visual color occurrence at indicated time points. All experiments were performed in triplicate.

\section{Clonogenic cell assay}

AGS cells were grown to about $80 \%$ confluence in $35 \mathrm{~mm}$ dishes. Then, cells were transfect with miR mimics or miR-control at 50nM concentration. Following, cells were exposed to $0,2,4$ and 8 Gy X-ray irradiation (6 MV, the dose rate was $200 \mathrm{~Gy} / \mathrm{min}$ ) by a PRIMUS accelerator (SIEMENS Medical Solutions, Erlangen, Germany). Cells (100 for cells irradiated with 0 or $2 \mathrm{~Gy}$, 200 for 4 Gy and 2000 for 8 Gy) were counted and cultured for clonogenic assay. The colony was formed in 7 days. Then, we stained the cells with crystal violet $(0.005 \%)$ for $20 \mathrm{~min}$ and recorded the colony numbers using Alpha Innotech (San Leandro, CA, USA) imaging software. Plating efficiency (PE) was calculated as: $\mathrm{PE}$ $=($ colony number/plating cell number $) \times 100 \%$, in triplicate.

\section{Western blotting}

Cells were lysed in lysis buffer $(20 \mathrm{mM}$ Tris HCL pH 8, 137 mM NaCl, 10\% glycerol, 1\% NP-40, 2 mM EDTA, protease and phosphatase inhibitors) followed by sonication on ice. Supernatants were fractionated by $10 \%$ SDSPAGE gels and electro-transferred onto nitrocellulose membranes (Millipore) after centrifuged at 14,000 g for $30 \mathrm{~min}$ at $4^{\circ} \mathrm{C}$. The membranes were incubated by primary antibodies. Then, the signals were acquired by using the ECL detection systems (Super Signal West Femto, Pierce) after incubated with horseradish-peroxidase-conjugated secondary antibodies (Pierce). Primary antibodies were used as follows. Rabbit antibodies against human H2AX, phospho-ATM (S1981), ATM, and Chk1were purchased from Cell Signaling Technologies, Beverly, MA, USA. Anti- $\beta$-actin (Sigma) was used as internal con- trol. The Western blotting images of three independent experiments were scanned and quantified by Image $\mathrm{J}$ software (National Institutes of Health). Band intensities were assessed and normalized to the $\beta$-actin bands as indicated experiments.

\section{Luciferase reporter assay}

3'-UTR of H2AX (position -19 to 1046) and Chk1 was amplifed by PCR and cloned into pGL3 (Promega) to obtain pGL3-H2AXUTR plasmid and pGL3-Chk1UTR plasmid (Lezina et al., 2013; Wang et al., 2011). The luciferase-UTR reporter plasmid that contains ATM 3'-UTR carrying a putative let-7g miRNA binding site (22102569) was constructed and inserted into pGL3-Luc vector named as pUTR (Yan et al., 2010). The constructs and the internal control vector pRL-TK (Promega) were co-transfected into $293 \mathrm{~T}$ cells. Cells were transfect with $50 \mathrm{nM}$ of miR-let- $7 \mathrm{~g}$ mimics or miR-control $6 \mathrm{hr}$ later. Luciferase reporter assays were performed after 24-hr transfection by the Dual-Luciferase Assay System (Promega) according to the manufacturer's instructions.

\section{Data analysis}

All data were calculated as mean \pm S.E.M. Student t-test was used to compare two groups. Comparison among multiple samples was made by ANOVA. The SPSS 18.0 was used for statistical analysis. $\mathrm{P}<0.05$ was considered a statistically significant difference.

\section{RESULTS}

\section{$\mathrm{H}_{2} \mathrm{O}_{2}$ resulted in the dysregulation of Hsa-Let-7g miRNA and DNA repair genes in GC cells}

Reactive Oxygen Species (ROS) induced by oxidative stress, including $\mathrm{H}_{2} \mathrm{O}_{2}$, have been known to stimulate DNA damage response (DDR) (Chen et al., 2012). To survey the possible mechanism of how $\mathrm{H}_{2} \mathrm{O}_{2}$ induced DDR in GC cells, we assayed the induction of DDR genes (ATM, H2AX and Chk1), as these agents are considered the key members of the DDR pathway (Shrivastav et al., 2008). The three DDR members were measured in mRNA level and protein level. It was found that both $100 \mu \mathrm{M}$ and $200 \mu \mathrm{M} \mathrm{H}_{2} \mathrm{O}_{2}$ promoted significant upregulation of ATM mRNA expression at $6 \mathrm{hr}\left(\mathrm{P}=0.011\right.$ in $200 \mu \mathrm{M} \mathrm{H}_{2} \mathrm{O}_{2}$ group $)$ and $12 \mathrm{hr}(\mathrm{P}=0.012$ and $\mathrm{P}=0.001$ respectively $)$, compared to the $\mathrm{C}$ group (without treatment of $\mathrm{H}_{2} \mathrm{O}_{2}$ ) (Fig. 1A). Moreover, the levels of H2AX (Fig. 1B) and Chk1 (Fig. 1C) were significantly high in mRNA expression under $200 \mu \mathrm{M} \mathrm{H}_{2} \mathrm{O}_{2}$ exposure at $6 \mathrm{hr}(\mathrm{P}=0.047$ for $\mathrm{H} 2 \mathrm{AX})$ and $12 \mathrm{hr}(\mathrm{P}=0.011$ for $\mathrm{H} 2 \mathrm{AX}$ and $\mathrm{P}=0.004$ for 
H. Hu et al.

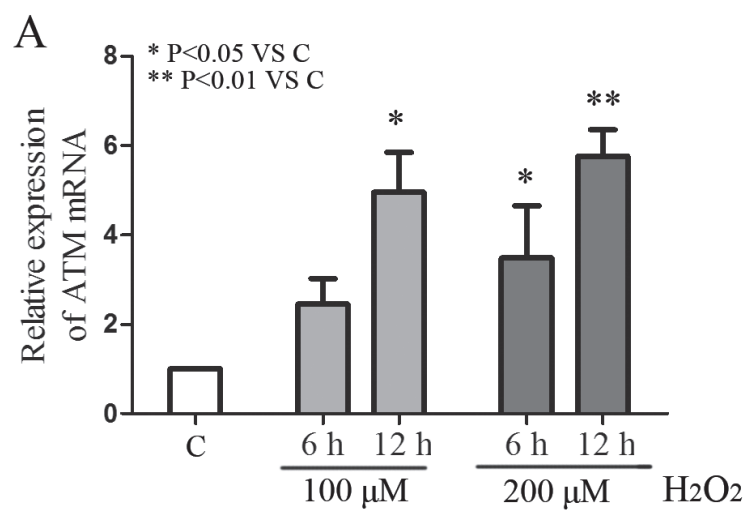

$\mathrm{C}$
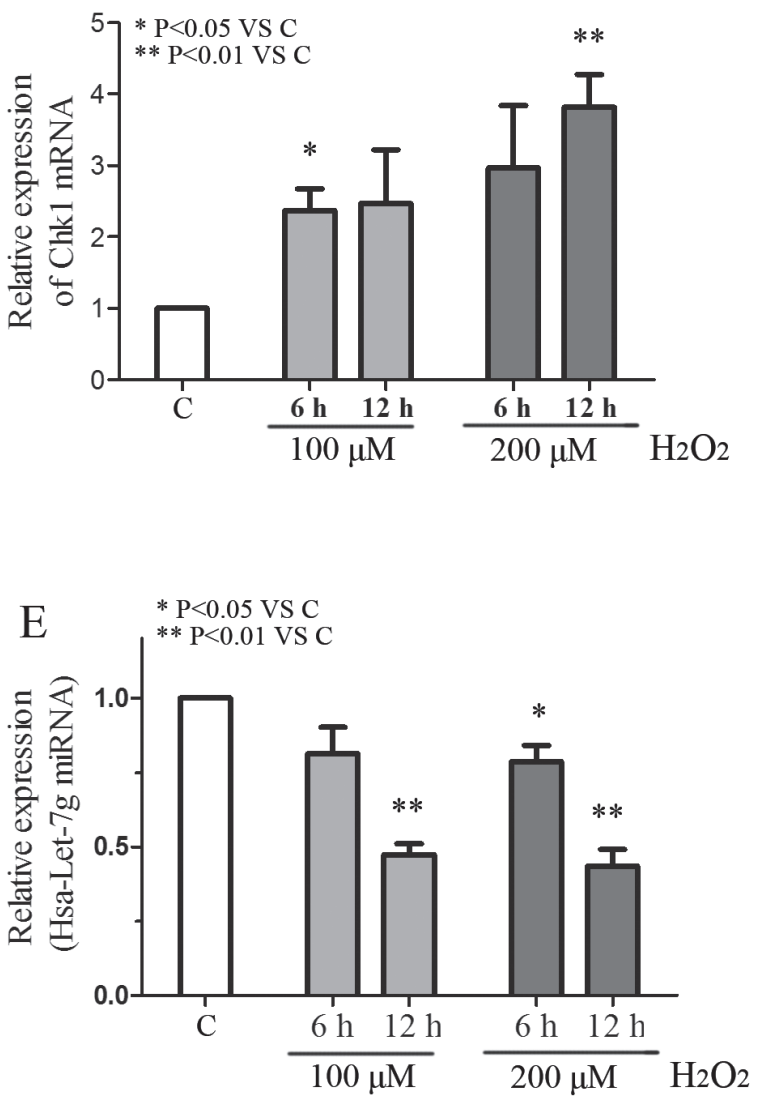

B

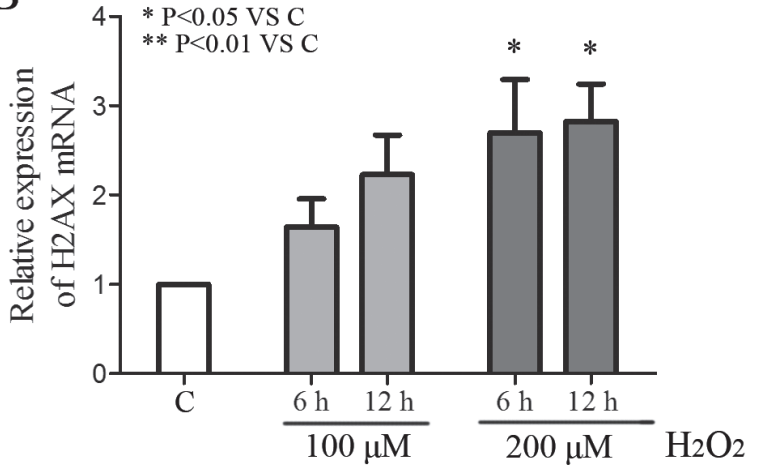

D

ATM
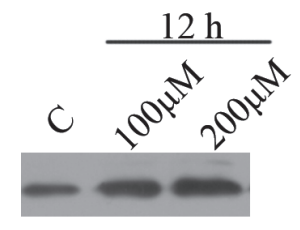

pATM

H2AX

Chk 1

$\beta$-actin

Fig. 1. $\mathrm{H}_{2} \mathrm{O}_{2}$ resulted in the dysregulation of hsa-let-7g miRNA and DNA repair genes in AGS cells. Cells were treated with $\mathrm{H}_{2} \mathrm{O}_{2}$ at concentrations of $100 \mu \mathrm{M}$ and $200 \mu \mathrm{M}$ for $6 \mathrm{hr}$ or $12 \mathrm{hr}$. Total RNA or proteins were extracted at the indicated time points. Expression of ATM mRNA (A), H2AX mRNA (B) and Chk1 mRNA (C) was assayed with qRT-PCR. GAPDH gene was denoted as endogenous control. Let-7g miRNA was tested with MirVana qRT-PCR miRNA Detection Kit and the U6 small nuclear RNA was internal control of miRNAs (E). The data were normalized by $2^{-\Delta \Delta C t}$ method as relative quantification. Results were indicated as mean \pm S.E.M. The ATM, H2AX, and Chk1 proteins and phosphorylated ATM proteins (pATM) were measured by Western blotting (D). ${ }^{*} \mathrm{P}<0.05$ was considered a statistically significant difference. 
Let- $7 \mathrm{~g}$ regulates DDR to repress $\mathrm{GC}$ under stress

Chk1 respectively), when compared with the $\mathrm{C}$ groups. In addition, there were obvious changes in ATM, H2AX and Chk1 protein expression between cells exposed to $\mathrm{H}_{2} \mathrm{O}_{2}$ with normal cells (without treatment of $\mathrm{H}_{2} \mathrm{O}_{2}$ ). Our investigation of phosphorylated ATM (pATM) showed the level of pATM in cells exposed to $\mathrm{H}_{2} \mathrm{O}_{2}$ was dramatically higher than that in AGS cells without exposure, as shown in Fig. 1D. To observe the effects of $\mathrm{H}_{2} \mathrm{O}_{2}$ on hsa-let-7g in GC cells, the expression of let- $7 \mathrm{~g}$ was measured by qRTPCR (Fig. 1E). The hsa-let-7g expression in AGS after $\mathrm{H}_{2} \mathrm{O}_{2}$ exposure for $12 \mathrm{hr}$ was significantly lower than in AGS cells without treatment $(\mathrm{P}=0.004$ and $\mathrm{P}=0.001$ for $100 \mu \mathrm{M}$ and $200 \mu \mathrm{M}$ respectively), as shown in Fig. 1E.

\section{Hsa-let-7g promoted apoptosis and inhibited cellular viability in the presence of $\mathrm{H}_{2} \mathrm{O}_{2}$}

To further study the effects of let-7g on GC cells upon oxidative stress, the hsa-let-7g mimics $(50 \mathrm{nM})$ were performed to increase the amount of let-7g by transfec- tion. The expression of let-7g increased to 973 fold and 643 fold post 24-hr transfection and 48-hr transfection respectively (Fig. 2A). Of note, addition of let-7g miRNA mimics significantly increased the apoptotic rate in the presence of $100 \mu \mathrm{M} \mathrm{H}_{2} \mathrm{O}_{2}$, in contrast with that in the miR-control group $(\mathrm{P}=0.017$ for $24 \mathrm{hr}, \mathrm{P}=0.028$ for $48 \mathrm{hr}$ ), as shown in Fig. 2B. The cellular proliferation was measured with MTT assay. It was found that cells with let- $7 \mathrm{~g}$ miRNA mimics had higher proliferation than that with miR-control not only at $24 \mathrm{hr}$ but also $48 \mathrm{hr}$ under $100 \mu \mathrm{M} \mathrm{H}_{2} \mathrm{O}_{2}$ exposure (Fig. 2C). These findings illustrated hsa-let-7g miRNA contributed to the apoptosis and loss of proliferation in $\mathrm{GC}$ cells exposed to $\mathrm{H}_{2} \mathrm{O}_{2}$.

\section{Hsa-let-7g repressed activation of DDR upon oxidative stress indirectly.}

Given the effect of $\mathrm{H}_{2} \mathrm{O}_{2}$ on DDR genes and the regulatory effect of let- $7 \mathrm{~g}$ on cellular apoptosis and proliferation upon oxidative stress, we supposed whether let-7g
A

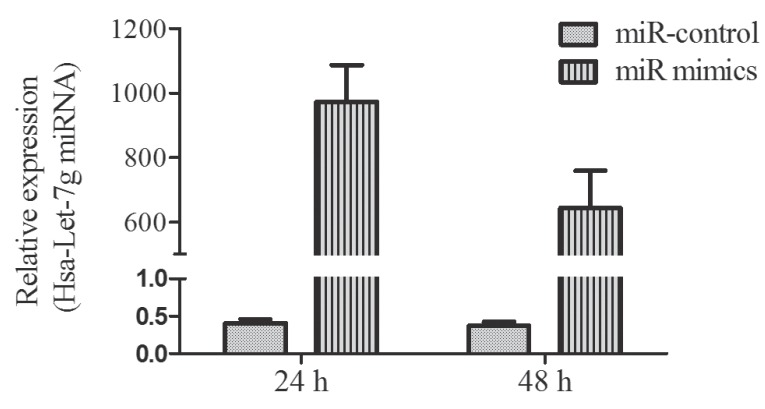

$\mathrm{B}$

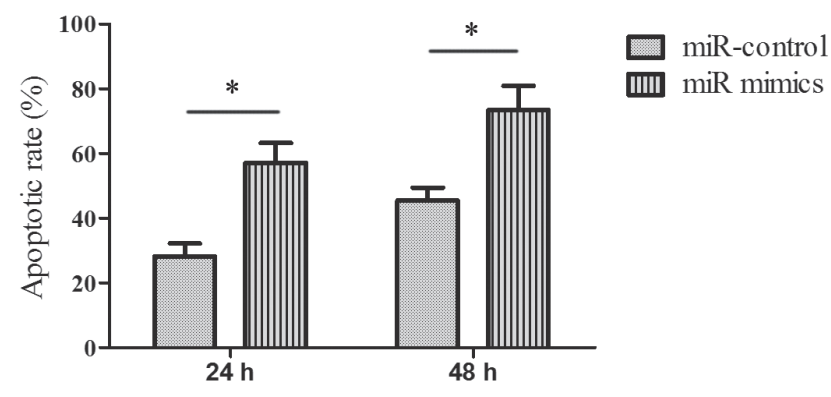

$\mathrm{C}$

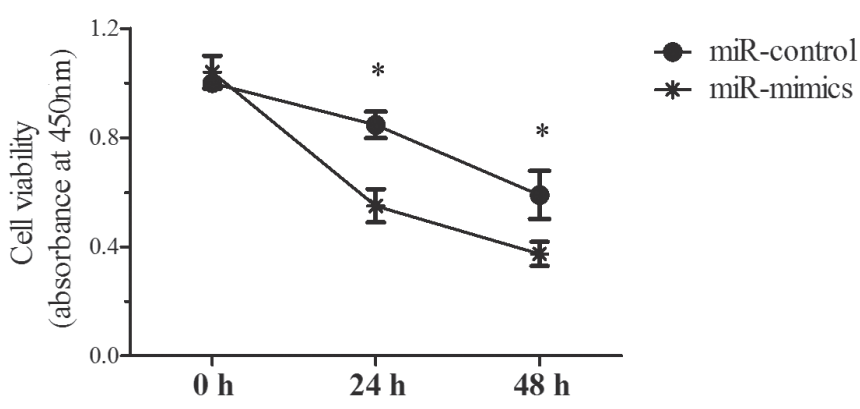

Fig. 2. Let- $7 \mathrm{~g}$ miRNA increased the damages induced by $\mathrm{H}_{2} \mathrm{O}_{2}$ including stimulation of apoptosis and loss of cellular viability. AGS cells underwent $100 \mu \mathrm{M} \mathrm{H}_{2} \mathrm{O}_{2}$ treatments for 24 or $48 \mathrm{hr}$ after transfection with miR-let-7g mimics (miR-mimics) or miR-control at $50 \mathrm{nM}$ concentration. The efficiency of transfection was assessed with qRT-PCR (A). Then, the apoptosis rate was assayed with Annexin V-FITC apoptosis detection kit. Data were expressed as the percentage of apoptotic cells among the total cells (B). The viability was measured by CCK-8 assay (C). All experiments were performed in triplicate. $* \mathrm{P}<0.05$ was considered a statistically significant difference. 
H. Hu et al.

A

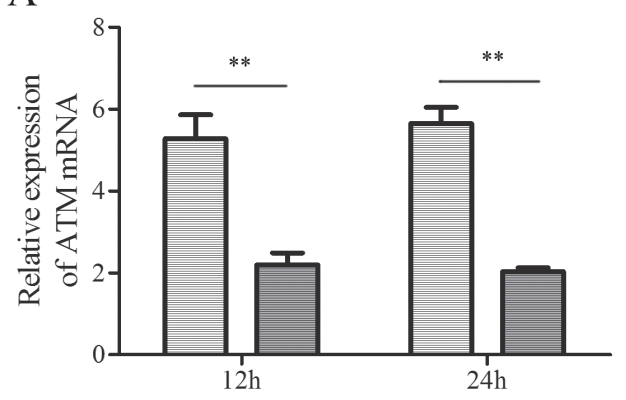

$\mathrm{C}$

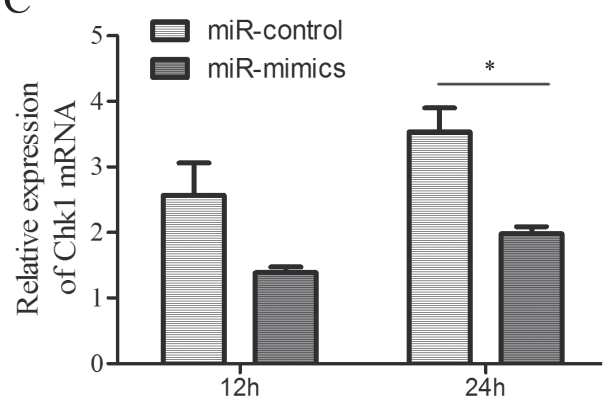

$\mathrm{E}$

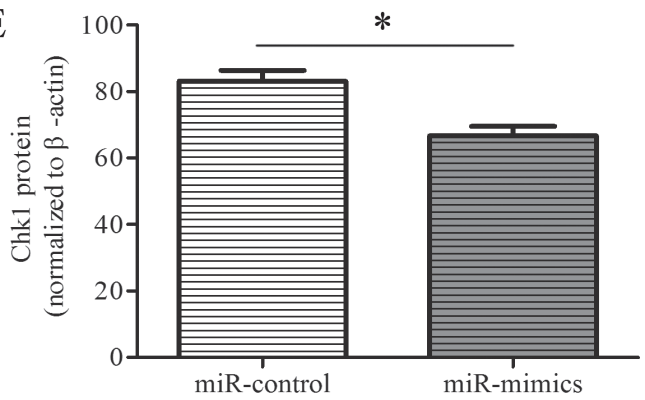

B
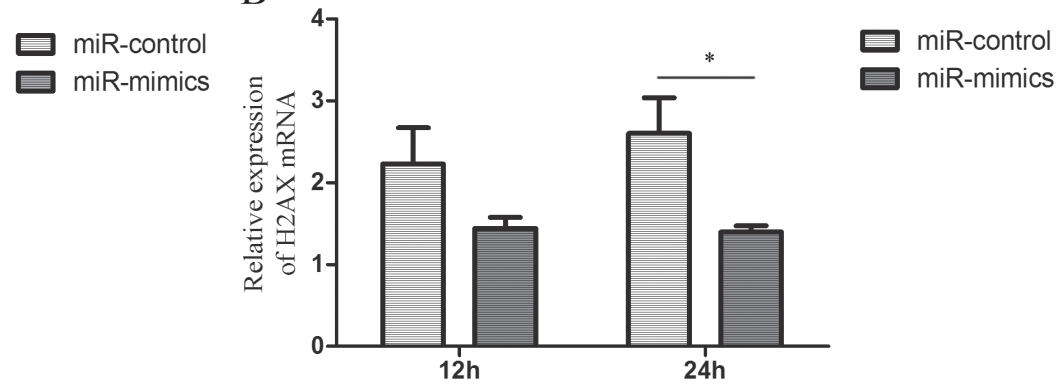

$\mathrm{D}$

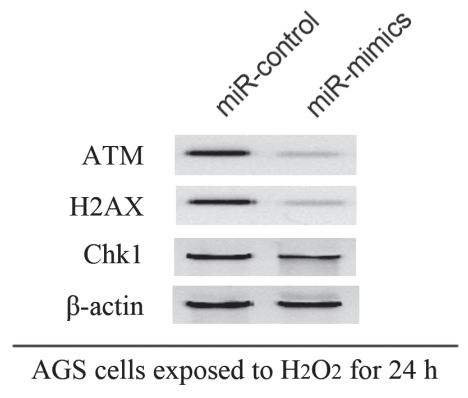

Fig. 3. Let-7g miRNA repressed the expression of DNA genes (ATM, H2AX and Chk1) in mRNA level and protein level. AGS cells underwent the indicated treatments in the presence of $100 \mu \mathrm{M} \mathrm{H}_{2} \mathrm{O}_{2}$. The expression of ATM (A), H2AX (B) and Chk1 (C) mRNA was assayed by qRT-PCR. Results were normalized by $2^{-\Delta \Delta C t}$ method and indicated as mean \pm S.E.M. The ATM, $\mathrm{H} 2 \mathrm{AX}$ and Chk1 proteins were compared between the miR-mimics group and the miR-control group (D). Band intensities of Chk1 protein were assessed by image J software and normalized to the $\beta$-actin bands (E). All experiments were performed in triplicate. The statistical results were indicated by asterisks $(\mathrm{P}<0.05)$ and $* *$ represents $\mathrm{P}<0.01$.

was related to the DDR genes upon oxidative stress. To confirm this hypothesis, the DDR genes including ATM, $\mathrm{H} 2 \mathrm{AX}$ and Chk1 were measured. Let-7g miRNA $(50 \mathrm{nM})$ decreased the expression of DDR genes (ATM, H2AX and Chk1) significantly at $24 \mathrm{hr}(\mathrm{P}=0.001, \mathrm{P}=0.049$ and $\mathrm{P}=0.014$ respectively) (Figs. 3A-3C). Moreover, let-7g also downregulated the level of ATM and H2AX in protein expression under $\mathrm{H}_{2} \mathrm{O}_{2}$ exposure for $24 \mathrm{hr}$ (Fig. 3D). We also found significant differences in Chk1 pro- tein between the miR-control group and the miR-mimics group, as shown in Fig. 3D and Fig. 3E $(\mathrm{P}=0.02)$.

To further investigate the relationship between let- $7 \mathrm{~g}$ and DDR genes, we provided four databases (TargetScan, microcosm, Pictar, mirtar) for let-7g candidates which could targeted 3' UTR of these genes (ATM, H2AX and Chk1). Unfortunately, there was no seed sequence to be acquired (data not shown). To confirm the prediction, the 3' UTR of three genes were 
Let-7g regulates DDR to repress GC under stress

A

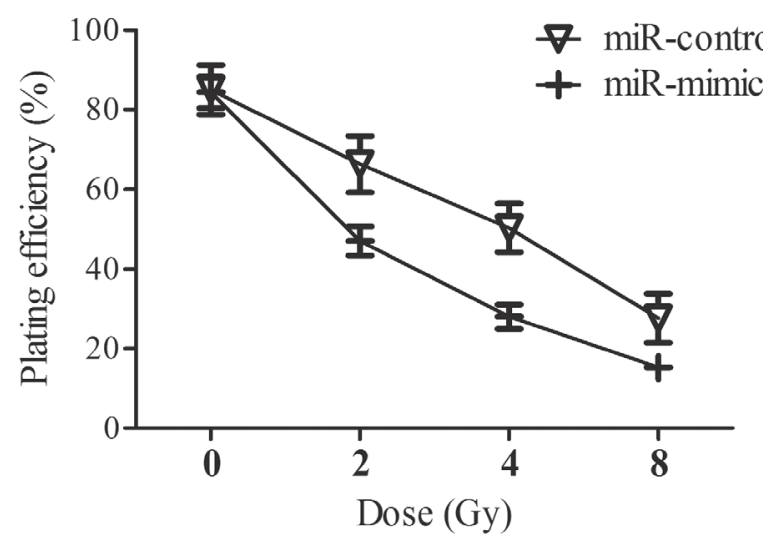

$\mathrm{C}$

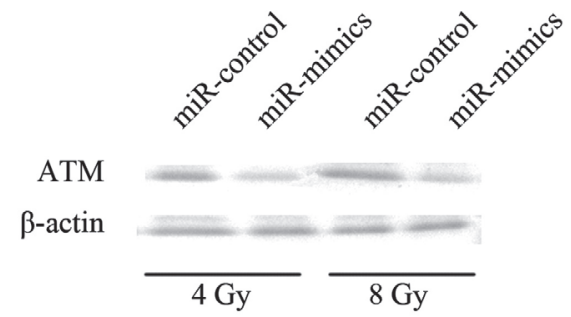

B

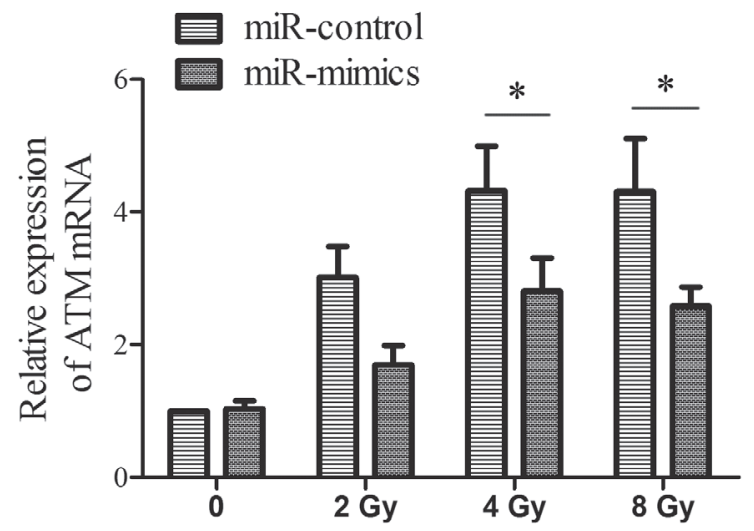

Fig. 4. Let-7g increased the sensitivity of GC cells to X-ray involving in activation of ATM gene. Cellular colony formation was assayed by clonogenic cell assay after exposure to $0,2,4$ and 8 Gy X-ray irradiation. Plating efficiency (PE) was calculated as: $\mathrm{PE}=($ colony number/plating cell number $) \times 100 \%$. Error bars indicate the standard error of the mean of three individual experiments (A). Cells were cultured for $24 \mathrm{hr}$ after exposure to 0, 2, 4 and $8 \mathrm{~Gy}$ X-ray irradiation. Next, the relative expression of ATM mRNA was measured (B). The ATM protein was assessed by Western blotting as well (C). All experiments were performed in triplicate. The statistical results were indicated by asterisks and ** represents $\mathrm{P}<0.01$.

inserted to pGL vector and luciferase reporter systems were constructed as described in Materials and Methods. There was no difference in the luciferease activity between constructs (pGL3-H2AXUTR and pGL3Chk1UTR) and pGL3, when let-7 mimics were applied (data not shown). Next, let-7g miRNA putative binding sites with most complementary base pairing of ATM 3'UTR were cloned into luciferase reporter constructs (pUTR) (Supplementary Fig. 1A). Luciferase reporter gene activity in pUTR was no significantly different from that in pGL in the presence/absence of let-7 mimics (Supplementary Fig. 1B). This further suggested that let$7 \mathrm{~g}$ might not target the DDR genes (ATM, H2AX and Chk1). However, let-7g significant repressed the activation of DDR indirectly.

\section{Let-7g increased the sensitivity of GC cells to $X$-rays}

Clonogenic assay was performed to detect the cell survival fractions after treatments with $0,2,4$, and 8 Gy X-ray irradiation. Plating efficiency of AGS was calculated as shown in Fig. 4A. The plating efficiency of AGS was $85.0 \%, 66 \%, 50 \%$ and $27.7 \%$ respectively in the miR-control group when exposed to $0,2,4$, and $8 \mathrm{~Gy}$. PE was $84 \%, 47 \%, 28 \%$ and $15 \%$ respectively, in AGS cells with miR-mimics when exposed to $0,2,4$, and 8 Gy (Fig. 4A). These data showed that let-7g increased the sensitivity of GC cells to X-rays dramatically. To determine whether the protective effects of let-7g against damage induced by X-rays were related to the DDR system, the ATM gene and ATM protein were measured in AGS cells exposed to X-rays for $24 \mathrm{hr}$. We found there were significant differences of expression of ATM gene mRNA between AGS cells with miR-control and cells with miR 
mimics $(\mathrm{P}=0.038$ under 4 Gy $\mathrm{X}$-ray irradiation and $\mathrm{P}=0.022$ under 8 Gy $\mathrm{X}$-ray irradiation respectively) (Fig. 4B). Let-7g mimics application decreased the level of ATM protein in AGS under X-ray stress (Fig. 4C). This implied that let-7g increased the sensitivity of GC cells to $\mathrm{X}$-ray involving in DDR system regulation.

\section{DISCUSSION}

Oxidative stress may cause chronic inflammation, which in turn induces the occurrence of chronic diseases, including cancers (Coussens and Werb, 2002). Extensive research has shown that oxidative stress is highly associated with the process of carcinogenesis, including survival, proliferation, angiogenesis and metastasis (Coussens and Werb, 2002; Mantovani, 2005). GC might be the product of oxidative stress as high risks of exposure that the gastric tissue suffers from the continuous oxidative stress and chronic inflammation (Farinati et al., 2008). To investigate the effects of oxidative stress on GC, we applied $\mathrm{H}_{2} \mathrm{O}_{2}$ to mimic the oxidative stress. Oxidative stress mediated the DNA damage to engage DNA damage response (DDR) systems, which are characterized by double-strand DNA breaks (DSBs) repair (Hoeijmakers, 2001). This mechanism is denoted as a signaling cascade referring to activation of ATM/ATR, the deposition of H2AX and Chk1/2 (Shrivastav et al., 2008; Mah et al., 2010).

The DNA damage response (DDR) is a kinase-based functional network primarily activated in response to different types of DNA lesions (Shrivastav et al., 2008). It initiates signaling cascades to activate cell cycle checkpoints according to triggered by early phosphorylationdriven signaling cascades including phosphorylation of ATM (ATM activation) followed by a delayed response that acted as activation and upregulatory expression of DDR genes (Matsuoka et al., 2007). Thereby, in our work, we identified the effects of oxidative stress and let$7 \mathrm{~g}$ on DDR according to examining the expression levels of DDR genes as well as the phosphorylated ATM. The expression of DDR genes and miRNA hsa-let-7g was surveyed to assess the effect of oxidative stress in GC cells. The DDR genes (ATM, H2AX and Chk1) were significantly increased at the level of proteins and mRNAs in the presence of $\mathrm{H}_{2} \mathrm{O}_{2}$ (Figs. 1A-1D). $\mathrm{H}_{2} \mathrm{O}_{2}$ stimulated the activation of DDR genes (overexpression of pATM, H2AX and Chk1) as well (Fig. 1D). These data illustrated $\mathrm{H}_{2} \mathrm{O}_{2}$ resulted in the DNA damages of GC cells and stimulated activation of the DDR systems. Further, the expression of hsa-let- $7 \mathrm{~g}$ was assayed to observe the effects of $\mathrm{H}_{2} \mathrm{O}_{2}$ on hsa-let- $7 \mathrm{~g}$ in $\mathrm{GC}$ cells. The hsa-let-7g expression in AGS after $\mathrm{H}_{2} \mathrm{O}_{2}$ exposure was significantly lower than in AGS cells without treatment $(p<0.05)$, as shown in Fig. 1E. The deregulation of let- $7 \mathrm{~g}$ under oxidative stress was similar to that under hydroxycamptothecin-induced stress (Wu et al., 2011).

Cellular apoptosis and viability possesses key effects on the mechanism for neoplastic progression (Evan and Vousden, 2001). We increased the let-7g expression level to study the effects of let- $7 \mathrm{~g}$ on apoptosis and viability of GC cells upon oxidative stress. Data revealed hsa-let-7g miRNA contributed to the apoptosis and loss of proliferation in GC cells exposed to $\mathrm{H}_{2} \mathrm{O}_{2}$. This meant hsa-Let-7g miRNA promoted the sensitivity of GC cells to oxidative stress. A previous study confirmed that let- $7 \mathrm{~g}$ regulated apoptosis to increase chemosensitivity of GC (Kim et al., 2011). Our study advances the understanding of the effect of let-7g on GC.

Hsa-let-7g miRNA has been described to inhibit proliferation and migration of hepatocellular carcinoma by targeting diverse genes (Lan et al., 2011; Chen et al., 2014). Instead, let- $7 \mathrm{~g}$ induced the increase of proliferation and reduction of apoptosis in normal cells by targeting antiangiogenic genes or apoptotic genes (Zhang et al., 2013). Thus, the effects exerted by let-7g as an inhibitor or promoter might be associated with microenvironment and its target genes. In this study, accumulating evidences may cast new light on the crosstalk between let-7g with DDR genes as previous results displayed upregulation of DDR genes and downregulation of let-7g under oxidative stress. Experiments proved let-7g was negative feedback link to expression of DDR genes according to exogenous addition of let-7g (Fig. 3). Moreover, there were no putative targets of let-7g in 3' UTR of ATM, H2AX and Chk1 by bioinformatics and experiments. We experimentally reconfirmed that let- $7 \mathrm{~g}$ didn't regulate putative binding sites with most complementary base pairing in 3' UTR of ATM directly according to the luciferase reporter system (Supplementary Fig. 1). Above all, let-7g did not directly target the DDR genes (ATM, H2AX and Chk1). However, let-7g significant repressed the activation of DDR indirectly. Of note, whether let-7g will target other DDR genes need to be further investigated as DDR systems contain lots of genes besides three main genes (ATM, H2AX and Chk1).

Ionizing radiation such as X-rays resulted in doublestrand DNA breaks (DSBs) is similar mechanism to free radicals (including ROS) caused (Hoeijmakers, 2001). Thus we concentrated on whether let-7g had the similar effects on GC cells under X-rays. Interestingly, hsalet- $7 \mathrm{~g}$ miRNA increased sensitivity of GC cells to X-rays (Fig. 4A). Simultaneously, downregulation of main DDR 
Let-7g regulates DDR to repress GC under stress

gene (ATM) was observed in $\mathrm{GC}$ with excessive let-7g amount under X-rays (Figs. 4B and 4C).

In summary, hsa-let-7g miRNA increased the sensitivity of GC to oxidative stress by repression activation of DDR indirectly. In addition, our data illustrated that let$7 \mathrm{~g}$ improved the effects of X-rays on GC cells involved in ATM regulation. Nevertheless, the direct target genes of let-7g need to be further investigated upon stress in GC. Our work provided available evidence for the antiGC mechanism of hsa-let-7g miRNA. We propose application of hsa-let-7g might be a promising therapeutic target for GC.

\section{ACKNOWLEDGMENTS}

This study was granted by the Affiliated Hospital of Inner Mongolia Medical University.

Conflict of interest---- The authors declare that there is no conflict of interest.

\section{REFERENCES}

Chen, B.P., Li, M. and Asaithamby, A. (2012): New insights into the roles of ATM and DNA-PKcs in the cellular response to oxidative stress. Cancer Lett., 327, 103-110.

Chen, K.C., Hsieh, I.C., Hsi, E., Wang, Y.S., Dai, C.Y., Chou, W.W. and Juo, S.H. (2011): Negative feedback regulation between microRNA let-7g and the oxLDL receptor LOX-1. J. Cell Sci., 124, 4115-4124.

Chen, K.J., Hou, Y., Wang, K., Li, J., Xia, Y., Yang, X.Y., Lv, G., Xing, X.L. and Shen, F. (2014): Reexpression of Let-7g microRNA inhibits the proliferation and migration via K-Ras/HMGA2/ snail axis in hepatocellular carcinoma. Biomed. Res. Int., 2014, 742417.

Chun-Zhi, Z., Lei, H., An-Ling, Z., Yan-Chao, F., Xiao, Y., Guang-Xiu, W., Zhi-Fan, J., Pei-Yu, P., Qing-Yu, Z. and Chun-Sheng, K. (2010): MicroRNA-221 and microRNA-222 regulate gastric carcinoma cell proliferation and radioresistance by targeting PTEN. BMC Cancer, 10, 367.

Correa, P. (2004): Is gastric cancer preventable? Gut, 53, $1217-$ 1219

Coussens, L.M. and Werb, Z. (2002): Inflammation and cancer. Nature, 420, 860-867.

Crosby, M.E., Kulshreshtha, R., Ivan, M. and Glazer, P.M. (2009): MicroRNA regulation of DNA repair gene expression in hypoxic stress. Cancer Res., 69, 1221-1229.

D'Autreaux, B. and Toledano, M.B. (2007): ROS as signalling molecules: mechanisms that generate specificity in ROS homeostasis. Nat. Rev. Mol. Cell. Biol., 8, 813-824.

Evan, G.I. and Vousden, K.H. (2001): Proliferation, cell cycle and apoptosis in cancer. Nature, 411, 342-348.

Farinati, F., Cardin, R., Cassaro, M., Bortolami, M., Nitti, D., Tieppo, C., Zaninotto, G. and Rugge, M. (2008): Helicobacter pylori, inflammation, oxidative damage and gastric cancer: a morphological, biological and molecular pathway. Eur. J. Cancer Prev., 17, 195-200.
Gencer, S., Cebeci, A. and Irmak-Yazicioglu, M.B. (2013): Matrix metalloproteinase gene expressions might be oxidative stress targets in gastric cancer cell lines. Chin. J. Cancer Res., 25, 322333.

He, J., Hua, J., Ding, N., Xu, S., Sun, R., Zhou, G., Xie, X. and Wang, J. (2014): Modulation of microRNAs by ionizing radiation in human gastric cancer. Oncol. Rep., 32, 787-793.

Hoeijmakers, J.H. (2001): Genome maintenance mechanisms for preventing cancer. Nature, 411, 366-374.

Hu, H., Du, L., Nagabayashi, G., Seeger, R.C. and Gatti, R.A. (2010): ATM is down-regulated by N-Myc-regulated microRNA-421. Proc. Natl. Acad. Sci. USA, 107, 1506-1511.

Hummel, R., Hussey, D.J. and Haier, J. (2010): MicroRNAs: predictors and modifiers of chemo- and radiotherapy in different tumour types. Eur. J. Cancer, 46, 298-311.

Hussain, S.P., Hofseth, L.J. and Harris, C.C. (2003): Radical causes of cancer. Nature reviews. Cancer, 3, 276-285.

Ishimoto, T., Sugihara, H., Watanabe, M., Sawayama, H., Iwatsuki, M., Baba, Y., Okabe, H., Hidaka, K., Yokoyama, N., Miyake, K., Yoshikawa, M., Nagano, O., Komohara, Y., Takeya, M., Saya, H. and Baba, H. (2014): Macrophage-derived reactive oxygen species suppress miR-328 targeting CD44 in cancer cells and promote redox adaptation. Carcinogenesis, 35, 1003-1011.

Kim, C.H., Kim, H.K., Rettig, R.L., Kim, J., Lee, E.T., Aprelikova, O., Choi, I.J., Munroe, D.J. and Green, J.E. (2011): miRNA signature associated with outcome of gastric cancer patients following chemotherapy. BMC Med. Genomics, 4, 79.

Lan, F.F., Wang, H., Chen, Y.C., Chan, C.Y., Ng, S.S., Li, K., Xie, D., He, M.L., Lin, M.C. and Kung, H.F. (2011): Hsa-let-7g inhibits proliferation of hepatocellular carcinoma cells by downregulation of c-Myc and upregulation of p16(INK4A). Int. J. Cancer, 128, 319-331.

Leung, W.K., Wu, M.S., Kakugawa, Y., Kim, J.J., Yeoh, K.G., Goh, K.L., Wu, K.C., Wu, D.C., Sollano, J., Kachintorn, U., Gotoda, T., Lin, J.T., You, W.C., Ng, E.K., Sung, J.J., Asia Pacific Working Group on Gastric Cancer. (2008): Screening for gastric cancer in Asia: current evidence and practice. Lancet Oncol., 9, 279287.

Lezina, L., Purmessur, N., Antonov, A.V., Ivanova, T., Karpova, E., Krishan, K., Ivan, M., Aksenova, V., Tentler, D., Garabadgiu, A.V., Melino, G. and Barlev, N.A. (2013): miR16 and miR-26a target checkpoint kinases Wee 1 and Chk1 in response to p53 activation by genotoxic stress. Cell Death Dis., 4, e953.

Liu, Y., Xing, R., Zhang, X., Dong, W., Zhang, J., Yan, Z., Li, W., Cui, J. and Lu, Y. (2013): miR-375 targets the p53 gene to regulate cellular response to ionizing radiation and etoposide in gastric cancer cells. DNA Repair, 12, 741-750.

Lowy, A.M., Clements, W.M., Bishop, J., Kong, L., Bonney, T., Sisco, K., Aronow, B., Fenoglio-Preiser, C. and Groden, J. (2006): beta-Catenin/Wnt signaling regulates expression of the membrane type 3 matrix metalloproteinase in gastric cancer. Cancer Res., 66, 4734-4741.

Mah, L.J., El-Osta, A. and Karagiannis, T.C. (2010): gammaH2AX: a sensitive molecular marker of DNA damage and repair. Leukemia, 24, 679-686.

Mantovani, A. (2005): Cancer: inflammation by remote control. Nature, 435, 752-753.

Matsuoka, S., Ballif, B.A., Smogorzewska, A., McDonald, E.R.3rd, Hurov, K.E., Luo, J., Bakalarski, C.E., Zhao, Z., Solimini, N., Lerenthal, Y., Shiloh, Y., Gygi, S.P. and Elledge, S.J. (2007): ATM and ATR substrate analysis reveals extensive protein net- 
works responsive to DNA damage. Science, 316, 1160-1166.

Nair, S., Norkus, E.P., Hertan, H. and Pitchumoni, C.S. (2000): Micronutrient antioxidants in gastric mucosa and serum in patients with gastritis and gastric ulcer: does Helicobacter pylori infection affect the mucosal levels? J. Clin. Gastroenterol., 30, 381-385.

Oberley, T.D. (2002): Oxidative damage and cancer. Am. J. Pathol., 160, 403-408.

Sanders, L.M., Henderson, C.E., Hong, M.Y., Barhoumi, R., Burghardt, R.C., Carroll, R.J., Turner, N.D., Chapkin, R.S. and Lupton, J.R. (2004): Pro-oxidant environment of the colon compared to the small intestine may contribute to greater cancer susceptibility. Cancer Lett., 208, 155-161.

Shen, L., Shan, Y.S., Hu, H.M., Price, T.J., Sirohi, B., Yeh, K.H., Yang, Y.H., Sano, T., Yang, H.K., Zhang, X., Park, S.R., Fujii, M., Kang, Y.K. and Chen, L.T. (2013): Management of gastric cancer in Asia: resource-stratified guidelines. Lancet Oncol., 14, e535-547.

Shrivastav, M., De Haro, L.P. and Nickoloff, J.A. (2008): Regulation of DNA double-strand break repair pathway choice. Cell Res., 18, 134-147.

Tang, C.H., Yamamoto, A., Lin, Y.T., Fong, Y.C. and Tan, T.W. (2010): Involvement of matrix metalloproteinase-3 in CCL5/ CCR 5 pathway of chondrosarcomas metastasis. Biochem. Pharmacol., 79, 209-217.

Tessitore, A., Cicciarelli, G., Del Vecchio, F., Gaggiano, A., Verzella, D., Fischietti, M., Vecchiotti, D., Capece, D., Zazzeroni, F. and Alesse, E. (2014): MicroRNAs in the DNA Damage/Repair Net- work and Cancer. Int. J. Genomics, 2014, 820248.

Tu, H., Sun, H., Lin, Y., Ding, J., Nan, K., Li, Z., Shen, Q. and Wei, Y. (2014): Oxidative stress upregulates PDCD4 expression in patients with gastric cancer via miR-21. Curr. Pharm. Des., 20, 1917-1923.

Valko, M., Rhodes, C.J., Moncol, J., Izakovic, M. and Mazur, M. (2006): Free radicals, metals and antioxidants in oxidative stressinduced cancer. Chem. Biol. Interact., 160, 1-40.

Wang, Y., Huang, J.W., Li, M., Cavenee, W.K., Mitchell, P.S., Zhou, X., Tewari, M., Furnari, F.B. and Taniguchi, T. (2011): MicroRNA-138 modulates DNA damage response by repressing histone H2AX expression. Mol. Cancer Res., 9, 1100-1111.

Wu, X.M., Shao, X.Q., Meng, X.X., Zhang, X.N., Zhu, L., Liu, S.X., Lin, J. and Xiao, H.S. (2011): Genome-wide analysis of microRNA and mRNA expression signatures in hydroxycamptothecin-resistant gastric cancer cells. Acta Pharmacol. Sin., 32, 259-269.

Yan, D., Ng, W.L., Zhang, X., Wang, P., Zhang, Z., Mo, Y.Y., Mao, H., Hao, C., Olson, J.J., Curran, W.J. and Wang, Y. (2010): Targeting DNA-PKcs and ATM with miR-101 sensitizes tumors to radiation. PLoS One, 5, e11397.

Zhang, Y., Chen, N., Zhang, J. and Tong, Y. (2013): Hsa-let-7g miRNA targets caspase- 3 and inhibits the apoptosis induced by oxLDL in endothelial cells. Int. J. Mol. Sci., 14, 22708-22720.

Zhao, L., Bode, A.M., Cao, Y. and Dong, Z. (2012): Regulatory mechanisms and clinical perspectives of miRNA in tumor radiosensitivity. Carcinogenesis, 33, 2220-2227. 